\title{
New constraints on seawater chemistry from Mesoarchean carbonates, Canada
}

\author{
LIYUAN LIANG $^{1 *}$, MUNIRA AFROZ ${ }^{2,3}$, PHILIP FRALICK ${ }^{2}$, \\ STEFAN V. LALONDE ${ }^{3}$, BRITTANY RAMSAY ${ }^{2}$, ROBERT \\ RIDING $^{1}$ \\ ${ }^{1}$ Department of Earth and Planetary Sciences, University of \\ Tennessee, Knoxville, Tennessee, USA \\ ${ }^{2}$ Geology Department, Lakehead University, Thunder Bay, \\ Ontario, Canada \\ ${ }^{3}$ CNRS-UMR6538 Géosciences Océan, European Institute \\ for Marine Studies, Plouzané, France \\ *Correspondence: 1liang1@utk.edu
}

New field observations show seaward margins of 2.8-2.95 Ga carbonate platforms in Red Lake Greenstone Belt (northwestern Superior province, Canada) contain iron oxide and calcium carbonate precipitates interlayered in proportions of $\sim 1: 5-1: 6$ thickness. Precipitation is inferred to have occurred as offshore anoxic seawater mixed with oxygenated water at the 'Oxygen Oasis' platform margin [1]. Iron formation deposited in the offshore basin is mainly chert, magnetite, pyritiferous carbonaceous slate and rare siderite [2]. Although likely altered during early diagenesis, these sediments suggest that offshore seawater chemistry favoured Fe-carbonates (e.g., siderite), and inhibited Ca-carbonate precipitation. Oxidation at the platform margin removed $\mathrm{Fe}^{2+}$ by precipitating iron (oxy)hydroxide. This in turn favoured first aragonite and then calcite precipitation to create the carbonate platforms.

Previous work suggests that Archean chemical sediments may be used to infer seawater composition and pCO2 if these minerals precipitated in the water column $[3,4,5]$. We used a thermodynamic speciation model to quantitatively evaluate the amounts of precipitates that would form at chemical equilibrium due to $\mathrm{Fe}^{2+}$ removal, by varring temperature, pCO2, $\mathrm{pH}, \mathrm{Ca}^{2+}$ and $\mathrm{Fe}^{2+}$ to set initial and equilibrium conditions. We then used the new field observations of the relative abundances of interlayered $\mathrm{CaCO}_{3}$ and iron oxide to constrain $\mathrm{Fe}$ and $\mathrm{Ca}$ concentrations in solution. This model in turn provides new estimates of $\mathrm{pH}$ and $\mathrm{p}_{\mathrm{CO} 2}$ values during the Mesoarchean, a critical time when large carbonate platforms began depositing for the first time in Earth history.

[1] Riding, Fralick \& Liang (2014), Precambrian Research 251, 232-237; [2] Fralick \& Riding (2015), Earth-Science Reviews 15, 132-175. [3] Holland (1984). The chemical evolution of the atmosphere and oceans. Princeton University Press. 582 pp. [4] Rosing, Bird, Sleep \& Bjerrum (2011). Nature 474, E4-E5. [5] Johnson, Ludois, Beard, Beukes \& Heimann (2013) Geology 41, 1147-1150. 